University of Nebraska - Lincoln

DigitalCommons@University of Nebraska - Lincoln

Faculty Publications from the Department of Electrical \& Computer Engineering, Department Electrical and Computer Engineering

3-15-1998

\title{
Ellipsometric determination of optical constants for silicon and thermally grown silicon dioxide via a multi-sample, multi- wavelength, multi-angle investigation
}

C. M. Herzinger

J. A. Woollam Co.

B. Johs

J. A. Woollam Co.

W. A. McGahan

J. A. Woollam Co.

John A. Woollam

J.A.Woollam Co., jwoollam1@unl.edu

W. Paulson

Advanced Products Research and Development Lab, Motorola, 3501 Ed Bluestein, Austin, Texas

Follow this and additional works at: https://digitalcommons.unl.edu/electricalengineeringfacpub

Part of the Electrical and Computer Engineering Commons

Herzinger, C. M.; Johs, B.; McGahan, W. A.; Woollam, John A.; and Paulson, W., "Ellipsometric determination of optical constants for silicon and thermally grown silicon dioxide via a multi-sample, multi-wavelength, multi-angle investigation" (1998). Faculty Publications from the Department of Electrical and Computer Engineering. 13.

https://digitalcommons.unl.edu/electricalengineeringfacpub/13

This Article is brought to you for free and open access by the Electrical \& Computer Engineering, Department of at DigitalCommons@University of Nebraska - Lincoln. It has been accepted for inclusion in Faculty Publications from the Department of Electrical and Computer Engineering by an authorized administrator of DigitalCommons@University of Nebraska - Lincoln. 


\title{
Ellipsometric determination of optical constants for silicon and thermally grown silicon dioxide via a multi-sample, multi-wavelength, multi-angle investigation
}

\author{
C. M. Herzinger, ${ }^{\text {a) }}$ B. Johs, W. A. McGahan, ${ }^{\text {b) }}$ and J. A. Woollam \\ J. A. Woollam Co., Research and Instrumentation, 645 Main Street, Suite 102, Lincoln, Nebraska 68508 \\ W. Paulson \\ Advanced Products Research and Development Lab, Motorola, 3501 Ed Bluestein, Austin, Texas 78721
}

(Received 26 February 1997; accepted for publication 26 November 1997)

\begin{abstract}
Optical constant spectra for silicon and thermally grown silicon dioxide have been simultaneously determined using variable angle of incidence spectroscopic ellipsometry from 0.75 to $6.5 \mathrm{eV}$. Spectroscopic ellipsometric data sets acquired at multiple angles of incidence from seven samples with oxide thicknesses from 2 to $350 \mathrm{~nm}$ were analyzed using a self-contained multi-sample technique to obtain Kramers-Kronig consistent optical constant spectra. The investigation used a systematic approach utilizing optical models of increasing complexity in order to investigate the need for fitting the thermal $\mathrm{SiO}_{2}$ optical constants and including an interface layer between the silicon and $\mathrm{SiO}_{2}$ in modeling the data. A detailed study was made of parameter correlation effects involving the optical constants used for the interface layer. The resulting thermal silicon dioxide optical constants were shown to be independent of the precise substrate model used, and were found to be approximately $0.4 \%$ higher in index than published values for bulk glasseous $\mathrm{SiO}_{2}$. The resulting silicon optical constants are comparable to previous ellipsometric measurements in the regions of overlap, and are in agreement with long wavelength prism measurements and transmission measurements near the band gap. (c) 1998 American Institute of Physics.
\end{abstract}

[S0021-8979(98)01006-8]

\section{INTRODUCTION}

Because of its technological importance, the optical properties of the $\mathrm{Si}-\mathrm{SiO}_{2}$ material system have been extensively studied. ${ }^{1-5}$ However, even though silicon is one of the most heavily studied and well-understood materials, the accuracy of reported optical constant spectra for crystalline silicon is still an issue. The original spectroscopic ellipsometry results for silicon obtained by Aspnes ${ }^{1}$ have been questioned (especially for energies less than $3.4 \mathrm{eV}$ ) by the work of Jellison using a two-channel polarization modulation ellipsometer. ${ }^{2}$ Aspnes' measurements were complicated both by the difficulty of stripping residual oxide without roughening the sample and by acquisition of ellipsometric data at an angle of incidence which pushed the measured ellipsometric values at smaller photon energies into a sub-optimal region for the rotating-analyzer ellipsometer (RAE) used. Jellison's work utilized a mathematical oxide removal procedure using separate intensity transmission measurement to establish the overlayer thickness. ${ }^{2}$ The $\mathrm{Si}-\mathrm{SiO}_{2}$ material system is further complicated by the recurring observation that when thermal $\mathrm{SiO}_{2}$ is modeled as a single homogenous layer, there is an apparent decrease in refractive index for $\mathrm{SiO}_{2}$ as the layer thickness increases. ${ }^{6,7}$ This apparent decrease is almost certainly due to a modeling artifact resulting from the well-

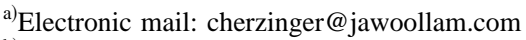

${ }^{b}$ Present address: Nanometrics, Inc., 310 De Guigne Dr., Sunnyvale, California 94086
}

established presence of an identifiable thin transition layer at the $\mathrm{Si}-\mathrm{SiO}_{2}$ interface with intermediate optical constants. ${ }^{3-7}$

For this work, measurements from six thermal oxide samples and one native oxide sample were analyzed in a self-contained, multi-sample technique utilizing spectroscopic and multi-angle data. These ellipsometric measurements cover a wider spectral range than previous publications with photon energies $\left(E_{\mathrm{ph}}\right)$ between 0.75 and $6.5 \mathrm{eV}$. These data were also acquired using a new auto-retarder (AR) equipped rotating-analyzer ellipsometer which permits accurate determination of the ellipsometric $\Delta$ over a full $360^{\circ}$ range. Optical data analyses, including ellipsometry, are critically dependent on proper modeling of the physical sample. Thus much of this work centers on finding an appropriate model for the oxide-interface-substrate combination and on systematically justifying the complexity of the final model selected. As the final result, optical constants for thermally grown $\mathrm{SiO}_{2}$ are obtained in conjunction with optical constants for the silicon substrate.

Section II gives a brief background on the variable-angle spectroscopic ellipsometry (VASE) terminology used. Section III details the measurement procedures used. Optical constants from many sources, including the final results of this work, are summarized in Section IV. The data analyses, consisting of a systematic sequence of increasingly complex optical models, are presented in Section V. Comparisons of optical constants from this work to other published ellipsometric and nonellipsometric results are presented in Section VI. 


\section{VASE BASICS}

Ellipsometry determines optical constants and thicknesses for materials in layered samples by fitting a parameterized model to the measured data. When simultaneously analyzing data from multiple samples, as in this work, the term "model" is generalized to encompass the set of all parameters needed to describe the structure of all measured samples. The standard, single-sample model for analyzing VASE data is a sequence of parallel layers with perfectly abrupt interfaces and homogenous optical constants, on a semi-infinite substrate. ${ }^{8}$ Our fitting procedure is described more fully elsewhere, ${ }^{9}$ but the basic terminology is given below. The standard ellipsometric parameters $\psi$ and $\Delta$ are related to the complex ratio of reflection coefficients for light polarized parallel $(p)$ and perpendicular $(s)$ to the plane of incidence. ${ }^{8}$ This ratio is defined as

$$
\rho=\frac{R_{p}}{R_{s}}=\tan (\psi) e^{i \Delta} .
$$

The electric field reflection coefficient for $p(s)$-polarized light is given by $R_{p}\left(R_{s}\right)$. In addition to $\psi$ and $\Delta$, standard deviations on the measured $\psi$ and $\Delta,\left(\sigma_{\psi}^{\exp }\right.$ and $\left.\sigma_{\Delta}^{\exp }\right)$ are estimated. The Levenberg-Marquardt algorithm ${ }^{10}$ is used to fit the model parameters by minimizing the following weighted (biased) test function ${ }^{11}$

$\xi^{2}=\frac{1}{2 N-M} \sum_{j=1}^{N}\left[\left(\frac{\psi_{j}^{\bmod }-\psi_{j}^{\exp d}}{\sigma_{\psi, j}^{\exp }}\right)^{2}+\left(\frac{\Delta_{j}^{\bmod }-\Delta_{j}^{\exp d}}{\sigma_{\Delta, j}^{\exp }}\right)^{2}\right]$.

The number of measured $\psi-\Delta$ pairs is $N$ and the total number of real valued fit parameters is $M$. To assess the quality of fits for this work for which different numbers of fit parameters are used, the value of $\xi$ with $M$ set to zero, $\xi_{0}$, is reported. The figure of merit (FOM) we use to describe confidence in the $i$ th fit parameter is given by

$$
\mathrm{FOM}_{i}=1.65 \times \sqrt{C_{i i}} \times \xi .
$$

This is the usual one-parameter, $90 \%$, uncorrelated confidence limit ${ }^{10}$ multiplied by our test function, $\xi$, where $C_{i i}$ is the $i$ th diagonal element of the fit parameter covariance matrix. ${ }^{9}$ This FOM combines information about the sharpness of the fit minimum $\left(C_{i i}\right)$ with information about the overall quality of the fit. Using the FOM as direct quantitative information about the sample is only valid when $\sigma_{\psi}^{\exp }$ and $\sigma_{\Delta}^{\exp }$ are known to be accurate in magnitude, and when random (not systematic) measurement errors are the dominant contribution to the FOM. ${ }^{9}$

\section{MEASUREMENTS}

For this investigation six thermal oxide samples (\#1-6) and one native oxide sample (\#7) were examined. The thermal oxide films were grown on lightly boron doped (14-22 $\Omega \mathrm{cm}),\langle 100\rangle$ oriented, $125 \mathrm{~mm}$ diam, standard complementary metal-oxide-semiconductor (CMOS) process silicon wafers. These samples were prepared at Motorola with nominal thicknesses of 10.5, 14.5, 35, 50, 100, and $350 \mathrm{~nm}$. Samples \#1-3 and \#5 were grown using dry $\mathrm{O}_{2}$ with a low $\mathrm{HCl}$ concentration, sample \#4 used pure $\mathrm{O}_{2}$, and sample \#6 used steam. Samples \#1-3 were grown at $900{ }^{\circ} \mathrm{C}$, \#4 at $1050{ }^{\circ} \mathrm{C}$, and \#5-6 at $1000^{\circ} \mathrm{C}$. Although slightly different, the oxidation process for each sample is expected to produce good quality interfaces without excessive roughening. The native oxide on sample \#7 was built up over a period of more than 2 years and no attempt was made to remove it. Although stripping oxide from silicon using HF is a standard technique, greater interest was placed on having the native oxide stable (not increasing thickness or changing composition) for the measurement cycle and in not adding surface roughness.

Data on all samples were acquired from 0.75 to $6.5 \mathrm{eV}$ using a J.A. Woollam Co. VASE ${ }^{\circledR}$ instrument. This rotatinganalyzer system was equipped with an AR input unit allowing the ellipsometric $\Delta$ parameter to be measured equally well over a full $360^{\circ}$ range. The performance of the AR system was tested in a straight through configuration, without a sample. In this configuration, the system proved capable of measuring $\psi$ to within $0.02^{\circ}$ of $45^{\circ}$ and $\Delta$ within $0.2^{\circ}$ of $0^{\circ}$ over the full spectral range.

For the six thermal oxides, data were acquired at $40^{\circ}$ and $75^{\circ}$ angles of incidence. The $75^{\circ}$ angle was chosen to keep the measured $\Delta$ 's around $90^{\circ}$ because this enhances sensitivity in the data analysis. ${ }^{12}$ Additional angles near $75^{\circ}$ were not deemed necessary because with the AR unit the ellipsometer worked well for all $\Delta$ values, and because the multisample nature of the experiment did not require additional effort on a particular sample to reduce noise. Relative to $75^{\circ}$, the $40^{\circ}$ angle was chosen to produce a large phase thickness difference for the probe beam traversing the oxide layers. Even though $\psi$ and $\Delta$ can be measured accurately at $40^{\circ}$, the
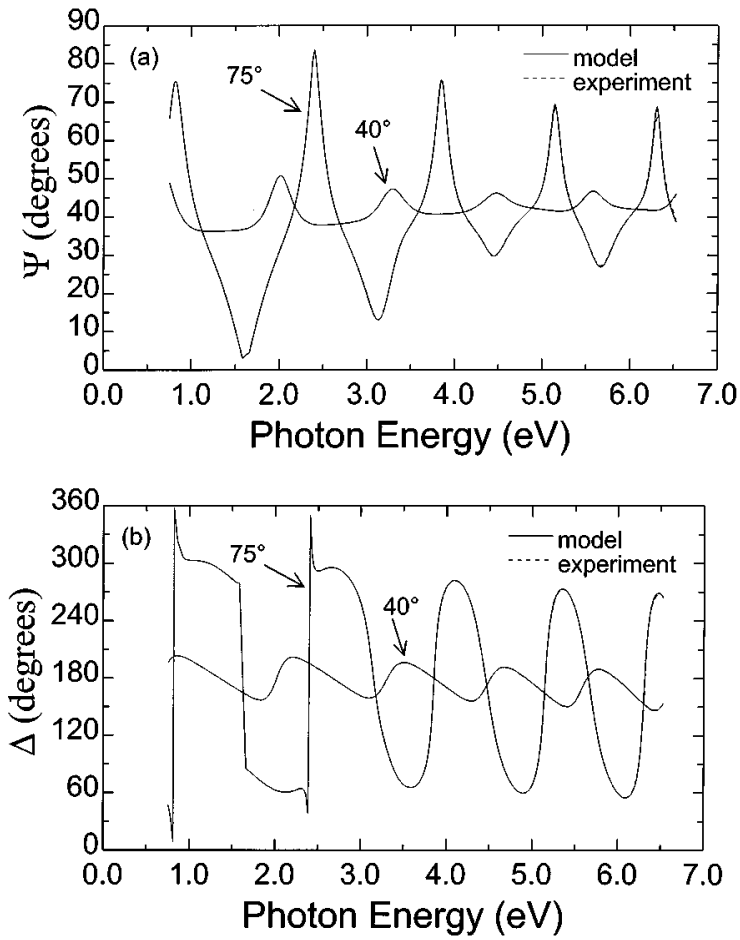

FIG. 1. Measured data compared with generated data from the final fit of this work [\#c4(iv)] for sample \#6 with a nominal oxide thickness of $350 \mathrm{~nm}$. The ellipsometric parameters $\psi$ and $\Delta$ are shown, respectively, in (a) and (b). The corresponding measured and generated curves are almost identical. 

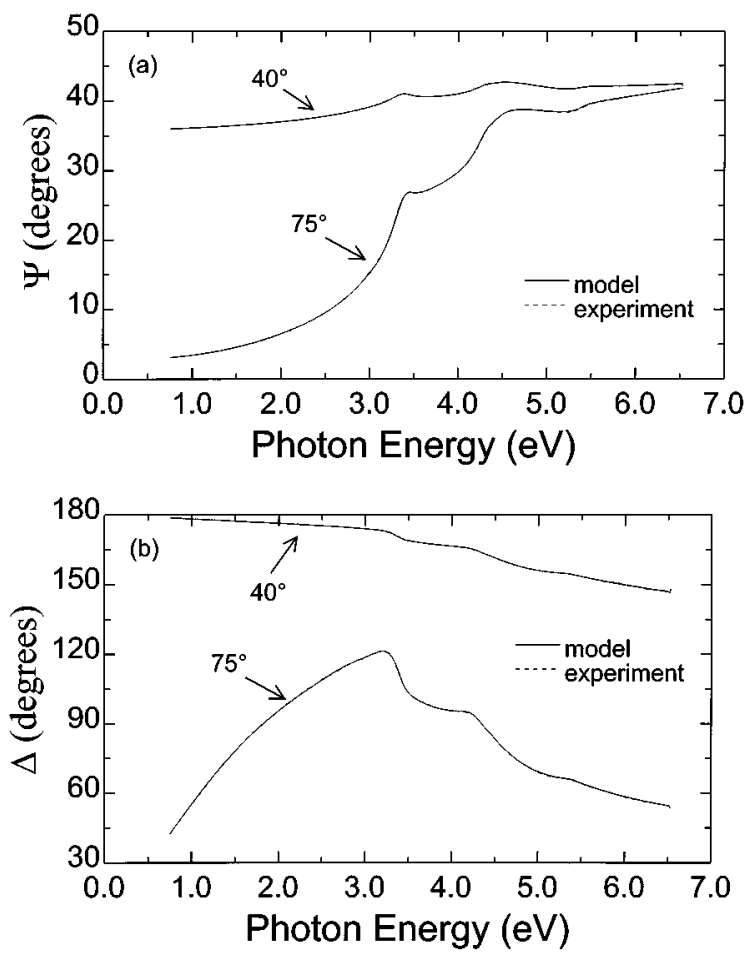

FIG. 2. Measured data compared with generated data from the final fit of this work [\#c4(iv)] for sample \#1 with a nominal oxide thickness of 10.5 $\mathrm{nm}$. The ellipsometric parameters $\psi$ and $\Delta$ are shown, respectively, in (a) and (b). The corresponding measured and generated curves are almost identical.

data analysis loses sensitivity for small angles of incidence. In certain cases such as a high index, slightly absorbing layer on a low index substrate, multiple angles can be used to fundamentally increase the information available about a sample. ${ }^{13}$ However, as in this experiment, the additional data at another angle of incidence serves mostly as a check on the $75^{\circ}$ data rather than providing significant additional information. The angles for the native-oxide sample $\left(70^{\circ}\right.$ and $\left.79^{\circ}\right)$ were chosen near to, but on either side of, the Brewster angle in the transparent spectral region of silicon in order to avoid measuring $\psi$ values near $0^{\circ}$.

Figure 1 shows measured data from sample \#6 (350 nm nominal) compared with generated data from this work's "best" model [fit \#c4(iv), infra] for both $\psi$ (a) and $\Delta$ (b). Figure 2 is similar to Fig. 1 except that data for sample \#1 $(10.5 \mathrm{~nm}$ nominal) is displayed. Note that the measured and calculated spectra are essentially identical. For many of the fits described in this work, the fit qualities are very good and differences between the models are not readily distinguished by simple visual inspection of the measured and calculated spectra. Only by examining a numerical quantity like the $\xi_{\text {o }}$ (see Section II) can the quality of different fits be objectively distinguished. To reduce random noise, the averaging time for each measurement was dynamically adjusted based on the detected probe-beam intensity. For the thermal oxide samples, the averaging time ranged from a minimum of $8 \mathrm{~s}$ to a maximum of $80 \mathrm{~s}$ for a single $\psi$ - $\Delta$ pair. For the native oxide sample which has a lower reflectivity and a large region of low $\psi$ values, the averaging time was increased to range from 66 to $670 \mathrm{~s}$. To minimize some potential systematic errors, the input polarizer tracked the measured $\psi$ values between $10^{\circ}$ and $80^{\circ}$. A total of five $\psi-\Delta$ pairs for two of the samples were removed because $\psi<3^{\circ}$ or $\psi>87^{\circ}$ and were thereby deemed potentially less accurate. To further minimize systematic errors, the measurement zone averaged over the input polarizer by acquiring data in two quadrants with the polarizer set near the $+\psi$ and $-\psi$ positions. The AR unit was used to add and subtract $40^{\circ}$ retardance at each polarizer position, and was also operated in a zone averaged manner. For each wavelength and incident angle combination, data taken using the AR was included with the usual RAE data taken without retardance in a regression model to find the most likely $\psi-\Delta$ pair that would match the measurements made with the system in its various configurations. The measurement error bars, $\sigma_{\psi}^{\text {exp }}$ and $\sigma_{\Delta}^{\text {exp }}$, used in the weighted fitting procedure for data analysis were derived from the regression statistics. Thus, $\sigma_{\psi}^{\exp }$ and $\sigma_{\Delta}^{\exp }$ incorporated both measurement noise effects and effects due to systematic errors. In a simple ellipsometric measurement without any form of zone averaging, systematic errors lead directly to errors in the $\psi-\Delta$ values, which are then assigned standard deviations based primarily on random noise. The principal purpose of assigning $\sigma_{\psi}^{\exp }$ and $\sigma_{\Delta}^{\exp }$ is to cause the fit algorithm to weight the best data points more heavily. Therefore, incorporating a systematic error component in $\sigma_{\psi}^{\exp }$ and $\sigma_{\Delta}^{\exp }$ is useful because both noisier as well as potentially less accurate data points are weighted less heavily.

\section{OPTICAL CONSTANTS}

This work evaluated multiple data analysis approaches using many different sets of optical constants from different sources, thus the optical constant descriptions have been centralized in this section rather than addressing them individually as they arise later. For this work, optical constants are presented both in complex dielectric $\left(\epsilon=\epsilon_{1}+i \epsilon_{2}\right)$ and complex refractive index $(N=\sqrt{\epsilon}=n+i k)$ forms. Table I summarizes the form, source, and use of the various sets of optical constants described in the text. Optical constants used in models for fitting ellipsometric data come in two primary forms: (1) tabulated wavelength-by-wavelength lists of dielectric values and (2) functions with adjustable parameters based on physical or empirical models. Tabulated optical constant lists are a traditional method of reporting results from ellipsometry and other characterization methods. Tabulated lists offer the greatest flexibility in describing a function and are convenient to work with as fit parameters because values at different wavelengths do not directly depend on each other. However, this flexibility means the noise in the experimental data is more easily passed along to the resulting optical constants, and the number of fit parameters scales directly with the number of wavelengths measured. Functional models are possible because real materials do not have random dielectric functions and there is a physical relationship between real and imaginary parts of the dielectric function given by the Kramers-Kronig (KK) integral. By fitting for the internal parameters, functional models allow determination of optical constants over wider spectral ranges 
TABLE I. Summary of optical constant sets used for this work.

\begin{tabular}{|c|c|c|c|}
\hline Name & Material & Form & Source/Use \\
\hline Glass-Palik & Bulk glass & Tabulated & $\begin{array}{l}\text { Prism }(E<5.8 \mathrm{eV}), \text { KK Reflection }(E>5.8 \mathrm{eV}) \text {, } \\
\text { Refs. } 14-16\end{array}$ \\
\hline Glass-Sellmeier & Bulk glass & Sellmeier & Fit to Glass-Palik for $0.75<E<6.5 \mathrm{eV}$ \\
\hline $\mathrm{SiO} 2-$ final & Thermal oxide & Sellmeier & Best fit from this work, Fit \#c4(iv) \\
\hline SiO2-Sellmeier & Thermal oxide & Sellmeier & $\begin{array}{l}\text { Indication that the Sellmeier parameters are being fitted } \\
\text { to describe thermal oxide optical constants }\end{array}$ \\
\hline $\mathrm{Si}-$ Aspnes & Silicon & Tabulated & Ellipsometry $(1.5<E<6.0 \mathrm{eV})$, Ref. 1 \\
\hline Si-Jellison & Silicon & Tabulated & Ellipsometry $(1.48<E<5.3 \mathrm{eV})$, Ref. 2 \\
\hline $\mathrm{Si}-$ final & Silicon & Parametric Model & This work $(0.75<E<6.5 \mathrm{eV})$, Fit \#c4(iv) \\
\hline $\mathrm{Si}$-Parametric & Silicon & Parametric Model & $\begin{array}{l}\text { Indication that a parametric model is being fitted to } \\
\text { describe the Si optical constants }\end{array}$ \\
\hline Si-Tabulated & Silicon & Tabulated & $\begin{array}{l}\text { Indication that a tabulated list is being fitted to } \\
\text { describe the } \mathrm{Si} \text { optical constants }\end{array}$ \\
\hline Si-Hulthèn & Silicon & Tabulated $k$ values & Transmission, Si on sapphire, Refs. 17,18 \\
\hline Si-McFarlane & Silicon & Tabulated $k$ values & Transmission, Polished Si, Refs. 17,19 \\
\hline $\mathrm{Si}-\mathrm{Dash}$ & Silicon & Tabulated $k$ values & Transmission, Polished Si, Ref. 20 \\
\hline EMA & Interface region & & $\begin{array}{l}\text { Bruggeman model to mix Si substrate and thermal } \\
\text { oxide optical constants, Ref. } 21\end{array}$ \\
\hline SiO-Palik & Silicon monoxide & Tabulated & KK reflection, used to model interface for some fits, Ref. 22 \\
\hline Native-Jellison & Native oxide on $\mathrm{Si}$ & Sellmeier & $\begin{array}{l}\text { Ellipsometry, only used to model interface layer for } \\
\text { some fits, Ref. } 2\end{array}$ \\
\hline Interface-final & Interface region & Sellmeier & Accepted interface optical constants for fit \#c4 \\
\hline Native-Sellmeier & Native oxide on $\mathrm{Si}$ & Sellmeier & $\begin{array}{l}\text { Indication that the Sellmeier parameters are being fitted } \\
\text { to describe thermal oxide optical constants }\end{array}$ \\
\hline Native-final & Native oxide on $\mathrm{Si}$ & Sellmeier & Result of best fit from this work, Fit \#c4(iv) \\
\hline
\end{tabular}

with fewer parameters, and they prevent some measurement noise from becoming part of the extracted optical constants. However, this same ability to screen out some noise can also smooth away or distort real spectral features. Therefore, functional optical constant models require attention to ensure a proper balance between flexibility and smoothing.

\section{A. Silicon dioxide}

In several fit schemes described later, different descriptions for $\mathrm{SiO}_{2}$ are used. One source of $\mathrm{SiO}_{2}$ optical constants is the tabulated values for glasseous $\mathrm{SiO}_{2}$ found in Palik's handbook (Glass-Palik). ${ }^{14-16}$ Below $5.8 \mathrm{eV}$, these data are the result of very precise prism beam-deviation measurements. ${ }^{15}$ There is a very slight mismatch (mostly in slope) with data at higher energies derived from a KK analysis of reflection data. ${ }^{16}$ As part of this work, a Sellmeier function of the following form with four adjustable parameters was fit to Palik's tabulated values

$$
n^{2}=o f f s e t+\frac{a \lambda^{2}}{\lambda^{2}-b^{2}}-c \lambda^{2} .
$$

The offset and $-c \lambda^{2}$ terms represent limits of a normal Sellmeier term with pole wavelengths respectively set to zero and to a very large, finite value. Using this Sellmeier form, a good representation of Glass-Palik values covering the range from 0.75 to $6.5 \mathrm{eV}$ was found with offset $=1.4923$, $a=0.61497, b=0.115 \mu \mathrm{m}$, and $c=0.01059 \mu \mathrm{m}^{-2}$. This set of optical constants (Glass-Sellmeier) produced agreement to within $0.001(0.07 \%)$ in refractive index over the entire fitted spectral range. For much of this work, the Sellmeier form was used when fitting for the oxide optical constants. The final results, $\mathrm{SiO}_{2}$-final [from fit \#c4(iv), infra] yielded the Sellmeier parameters of offset $=1.3000, a=0.81996$, $b=0.10396 \mu \mathrm{m}$, and $c=0.01082$. Figure 3 shows the refractive index for the three sets of oxide optical constants just described. At a wavelength of $546.1 \mathrm{~nm}$ the index of $\mathrm{SiO}_{2}$-final is 1.4655 which is slightly higher than for GlassPalik (1.4602) and Aspnes' thermal oxide value of $1.4631{ }^{7}$ Stress induced birefringence in the $\mathrm{SiO}_{2}$ has been noted by

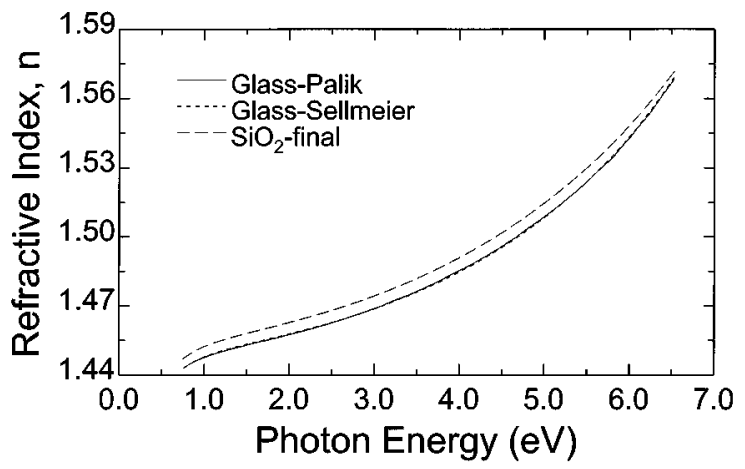

FIG. 3. Different refractive index functions used to model thermal oxide. The $\mathrm{SiO}_{2}-$ Sellmeier model was fit to published values from Palik for $\mathrm{SiO}_{2}$ glass (Glass-Palik). $\mathrm{SiO}_{2}$-final represents the final bulk oxide optical constants derived from this work for thermally grown oxide layers on silicon from the final fit of this work [\#c4(iv)]. 
Taft $^{6}$ and Aspnes, ${ }^{7}$ but is not included in the results presented here. The stress effect is small and its inclusion in the data analysis did not improve the fit quality.

\section{B. Silicon}

Historically, the standard source for silicon substrate optical constants has been Aspnes' ellipsometric results on a polished silicon substrate from 1.5 to $6.0 \mathrm{eV}$ ( $\mathrm{Si}$-Aspnes). ${ }^{1}$ Jellison has published a comparable set of optical constants for silicon covering the region from 1.48 to $5.3 \mathrm{eV}$ $\left(\mathrm{Si}\right.$-Jellison). ${ }^{2}$ Jellison's ellipsometric measurements were made on a silicon substrate with a native oxide and his reported optical constants accounted for the removal of 0.77 $\mathrm{nm}$ of oxide. The native oxide thickness was adjusted in such a way that the resulting $\mathrm{Si}-$ Jellison absorption values matched published values of Dash and Newman $(\mathrm{Si}-\mathrm{Dash})^{2,20}$ which have also been accepted by Aspnes as good values. ${ }^{1}$ Jellison's assumed model for native oxide optical constants (Oxide-Native) is described more fully below. Additional ellipsometric measurements of Si have been made on fresh epitaxial surfaces ${ }^{23}$ and on hydrogenterminated (111) samples, ${ }^{24}$ but these are not treated in detail here. Palik's handbook also tabulates two sets of silicon absorption values based on the intensity transmission measurements of McFarlane and Hulthèn. ${ }^{17-19}$ The McFarlane measurements spanning the very low absorption region from 1.0 to $1.3 \mathrm{eV}$ were performed on a mechanically polished single crystal sample. The Hulthèn values spanning $1.2-2 \mathrm{eV}$ were obtained from very thin epitaxial films on sapphire and there is a mismatch by a factor of 5 at $1.28 \mathrm{eV}$ as compared to McFarlane's values.

In addition to tabulated lists, this work used a parametric functional model to describe and fit the dielectric function for silicon. The mathematical details of this model are not discussed here, ${ }^{25}$ but the key elements of the model are that it is internally KK correct and based on Gaussian broadening and the superposition of critical point structures which are composed of continuous polynomial sections. For this model, 58 internal parameters were used in the fitting process (compare to 620 needed for tabulated dielectric values at 310 wavelengths). Correlations exist among these internal parameters, but since only the final calculated dielectric values are of interest rather than the internal model parameter values, the fact that multiple parameter sets can produce nearly identical dielectric functions is not a limiting concern. The dielectric values published by Aspnes and Jellison, and resulting from this work (Si-final) are compared in Fig. 4. (Tabulated values for Si-final are available electronically through the Physics Auxiliary Publication Service.)

\section{Interfacial layer}

The existence of an identifiable interface region is well established, but the exact nature is still the subject of debate. ${ }^{4,5,7}$ One commonly used model to simulate intermixing of materials at an interface is to assign optical constants for an interfacial layer using the Bruggeman effective media approximation (EMA). ${ }^{21}$ In satisfying the validity of the Bruggeman approximation, one assumes that the mixture is

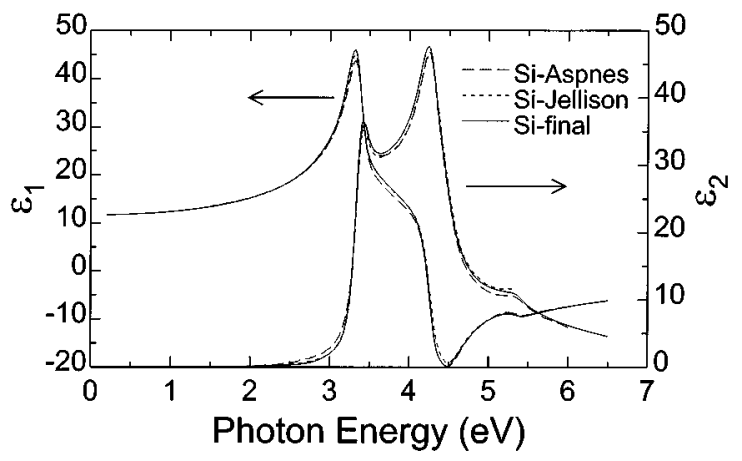

FIG. 4. Different complex dielectric functions used to model the silicon substrate. $\mathrm{Si}-$ Aspnes and $\mathrm{Si}-$ Jellison are previously published ellipsometric results. $\mathrm{Si}-$ final represents the final silicon optical constants derived from this work [\#c4(iv)].

reasonably described as segregated inclusions of one material in another in such a manner that the polarizability of each material is a valid approximation over the inclusion. When used with layers on the order of $1 \mathrm{~nm}$ thick and when the intermixing is nearly on the atomic scale, the EMA assumption may not be strictly satisfied, but it does provide a useful way to "average" two sets of optical constants and thereby simulate the softening of spectral reflection features due to a nonabrupt interface. Previous work using EMA interface models has simulated the mixing of $\mathrm{SiO}_{x}$ and crystalline $\mathrm{Si}$ with $\mathrm{SiO}_{2},{ }^{3}$ amorphous $\mathrm{Si}$ with $\mathrm{SiO}_{2},{ }^{7}$ and strained $\mathrm{Si}$ with $\mathrm{SiO}_{2}{ }^{5}$

Another possible approach to modeling the $\mathrm{Si}-\mathrm{SiO}_{2}$ transition region is to assume over a limited spatial extent that the mixing occurs fully on the atomic level (opposite extreme as compared to an EMA), and therefore to model the interface as a region of $\mathrm{SiO}$ (or $\mathrm{SiO}_{x}$ ) a few monolayers thick. Silicon monoxide optical constants are available in tabulated form (SiO-Palik). ${ }^{17,22}$ Aspnes' chemically intermixed layer of $\mathrm{Si}_{x}\left(\mathrm{SiO}_{2}\right)_{1-x}$ is a similar example. ${ }^{7}$

Another reasonable approach is to assume the interface layer is transparent and has a dispersion similar to $\mathrm{SiO}_{2}$. For example, native oxide on silicon may also be similar to the material in the $\mathrm{Si}-\mathrm{SiO}_{2}$ transition region in that both represent incomplete oxidation. Jellison has published a Sellmeier functional form describing native oxide (Native-Jellison) with Sellmeier parameters of offset $=1, a=2.0, b=0.09227$ $\mu \mathrm{m}$, and $c=0$. While this published model covered data only over Jellison's spectral range, it was extrapolated to the full $0.75-6.5 \mathrm{eV}$ range examined in this work. (Note, NativeJellison optical constants were not used in modeling the native oxide sample as part of this work.) This work also made use of Sellmeier functions to describe interfacial optical constants. There is very little sensitivity to the absolute value and spectral dispersion of the dielectric values of a very thin interfacial layer. Therefore, interfacial Sellmeier models used the $a, b$, and $c$ parameters used to describe glass $\left(\mathrm{SiO}_{2}-\right.$ Sellmeier $)$ and only the offset parameter was adjustable for fitting. The Sellmeier model values selected to described the interface for the final fit of this work (Interfacefinal) were offset $=3.5, a=0.69417, \quad b=0.115 \mu \mathrm{m}$, and $c=0.010591 \mu \mathrm{m}^{-2}$. 
TABLE II. Fit quality parameter, $\xi_{\mathrm{o}}$, for multi-sample fits in class \#a without interface layers. (Bracketed values were calculated, without refitting, for a common spectral range of $1.5-5.3 \mathrm{eV}$.)

\begin{tabular}{|c|c|c|c|c|c|c|c|}
\hline \multirow[b]{2}{*}{$\begin{array}{l}\text { Fit } \\
\text { group }\end{array}$} & \multirow[b]{2}{*}{ Oxide model } & \multicolumn{3}{|c|}{ Tabulated Si Opt cons } & \multicolumn{3}{|c|}{ Fitted Si Opt Cons } \\
\hline & & $\begin{array}{l}\text { (i) } \\
\text { Aspnes }\end{array}$ & $\begin{array}{l}\text { (ii) } \\
\text { Jellison }\end{array}$ & $\begin{array}{l}\text { (iii) } \\
\text { Final, fit } \\
\text { \#c4(iv) }\end{array}$ & $\begin{array}{c}\text { (iv) } \\
\text { Parametric } \\
\text { Si model }\end{array}$ & $\begin{array}{c}(v) \\
\lambda \text {-by- } \lambda \\
\text { Si only }\end{array}$ & $\begin{array}{c}\text { (vi) } \\
\lambda \text {-by- } \lambda \\
\text { fit all }\end{array}$ \\
\hline$\# \mathrm{a} 1$ & $\begin{array}{l}\text { Glass-Palik } \\
\text { fit thicknesses only }\end{array}$ & $\begin{array}{c}2.970 \\
{[3.138]}\end{array}$ & $\begin{array}{c}3.208 \\
{[3.213]}\end{array}$ & $\begin{array}{c}2.437 \\
{[2.743]}\end{array}$ & $\begin{array}{c}1.784 \\
{[1.902]}\end{array}$ & $\begin{array}{c}1.674 \\
{[1.690]}\end{array}$ & $\begin{array}{c}1.653 \\
{[1.780]}\end{array}$ \\
\hline$\# \mathrm{a} 2$ & $\begin{array}{l}\text { Glass-Sellmeier } \\
\text { fit thicknesses only }\end{array}$ & $\begin{array}{c}3.077 \\
{[3.272]}\end{array}$ & $\begin{array}{c}3.374 \\
{[3.379]}\end{array}$ & $\begin{array}{l}2.561 \\
{[2.917]}\end{array}$ & $\begin{array}{c}1.855 \\
{[2.008]}\end{array}$ & $\begin{array}{c}1.754 \\
{[1.900]}\end{array}$ & $\begin{array}{c}1.732 \\
{[1.811]}\end{array}$ \\
\hline$\# \mathrm{a} 3$ & $\begin{array}{c}\mathrm{SiO} 2-\text { Sellmeier } \\
\text { couple oxide opt. cons. } \\
\text { fit Sellmeier values }\end{array}$ & $\begin{array}{c}2.359 \\
{[2.511]}\end{array}$ & $\begin{array}{c}2.602 \\
{[2.605]}\end{array}$ & $\begin{array}{c}1.694 \\
{[1.961]}\end{array}$ & $\begin{array}{l}1.390 \\
{[1.494]}\end{array}$ & $\begin{array}{c}1.271 \\
{[1.297]}\end{array}$ & $\begin{array}{c}1.120 \\
{[1.134]}\end{array}$ \\
\hline$\# \mathrm{a} 4$ & $\begin{array}{l}\mathrm{SiO} 2-\text { Sellmeier } \\
\text { uncoupled oxide opt. cons. } \\
\text { fit Sellmeier offset } \text { only }\end{array}$ & $\begin{array}{c}2.697 \\
{[2.893]}\end{array}$ & $\begin{array}{c}3.119 \\
{[3.125]}\end{array}$ & $\begin{array}{c}2.013 \\
{[2.314]}\end{array}$ & $\begin{array}{c}1.472 \\
{[1.533]}\end{array}$ & $\begin{array}{c}1.319 \\
{[1.383]}\end{array}$ & $\begin{array}{c}1.263 \\
{[1.226]}\end{array}$ \\
\hline$\#$ a5 & $\begin{array}{c}\mathrm{SiO} 2-\text { Sellmeier } \\
\text { uncoupled oxide opt. cons. } \\
\text { fit all Sellmeier values }\end{array}$ & $\begin{array}{c}2.198 \\
{[2.349]}\end{array}$ & $\begin{array}{c}2.109 \\
{[2.113]}\end{array}$ & $\begin{array}{c}1.368 \\
{[1.562]}\end{array}$ & $\begin{array}{c}1.144 \\
{[1.193]}\end{array}$ & $\begin{array}{c}1.018 \\
{[1.071]}\end{array}$ & $\begin{array}{c}0.811 \\
{[0.788]}\end{array}$ \\
\hline
\end{tabular}

\section{DATA ANALYSIS}

When performing a model dependent data analysis, simple models are preferable to complex ones if the fit quality is the same. Incorporated within this paradigm is that one should use previously measured optical constants if a reasonable fit can be obtained, and that one should not include interfaces unless necessary. The difficulty is in objectively evaluating the quality of the fit as each model complication is added to see if the fit really improved. Of course, if the fit does not get better with increasing complexity, that does not mean the complex model is necessarily wrong, but it does mean that one lacks sensitivity to allow a distinction and some other criteria must be employed. The majority of this work involves the systematic examination of increasingly complex models, with the fit quality examined at each stage to evaluate the necessity of including each feature.

Part A of this section covers certain key concepts which are applicable to all analysis procedures described. Next, the three main classes of fits (\#a-c) are discussed in turn. Class \#a examines models without interface layers. Five different modeling approaches for the $\mathrm{SiO}_{2}$ optical constants were considered in this class. In class \#b, models with four differ- ent interface descriptions were examined using existing values for $\mathrm{SiO}_{2}$. Fit class \#c also examined four interface models, but the oxide optical constants were also fitted. The results for each class are summarized in Tables II-IV. In the final part of this section, the considerations used in settling upon the final, "best" results are examined as they relate to correlation effects involving optical constants for the modeled interface layer.

\section{A. Key concepts}

(1) All fits performed for this work were multi-sample regressions of multi-angle, spectroscopic data. When the full spectral range was fit, $4335 \psi-\Delta$ pairs from seven samples at 310 wavelengths were simultaneously analyzed. Each sample had its own associated layered model with independently adjustable thicknesses. The key to a multi-sample analysis is the manner in which the optical constant are coupled together among the samples. (Thicknesses were never coupled between samples.) Using the same optical constants for different samples is a simplifying assumption that is difficult to prove directly (especially when interface layers are permitted in the model), but the results presented

TABLE III. Fit quality parameter, $\xi_{\mathrm{o}}$, for multi-sample fits in class \#b with interface layers, but using tabulated values (Glass-Palik) for $\mathrm{SiO}_{2}$. (Bracketed values were calculated, without refitting, for a common spectral range of $1.5-5.3 \mathrm{eV}$.)

\begin{tabular}{|c|c|c|c|c|c|c|c|}
\hline \multirow[b]{2}{*}{$\begin{array}{l}\text { Fit } \\
\text { group }\end{array}$} & \multirow[b]{2}{*}{ Interface model } & \multicolumn{3}{|c|}{ Tabulated Si Opt Cons } & \multicolumn{3}{|c|}{ Fitted Si Opt Cons } \\
\hline & & $\begin{array}{c}\text { (i) } \\
\text { Aspnes }\end{array}$ & $\begin{array}{l}\text { (ii) } \\
\text { Jellison }\end{array}$ & $\begin{array}{c}\text { (iii) } \\
\text { Final, fit } \\
\text { \#c4(iv) }\end{array}$ & $\begin{array}{c}\text { (iv) } \\
\text { Parametric } \\
\text { Si model }\end{array}$ & $\begin{array}{c}\text { (v) } \\
\lambda \text {-by- } \lambda \\
\text { Si only }\end{array}$ & $\begin{array}{c}\text { (vi) } \\
\lambda \text {-by- } \lambda \\
\text { fit all }\end{array}$ \\
\hline$\# \mathrm{~b} 1$ & EMA & $\begin{array}{c}2.460 \\
{[2.559]}\end{array}$ & $\begin{array}{c}2.901 \\
{[2.905]}\end{array}$ & $\begin{array}{c}1.899 \\
{[1.985]}\end{array}$ & $\begin{array}{c}1.631 \\
{[1.711]}\end{array}$ & $\begin{array}{c}1.563 \\
{[1.630]}\end{array}$ & $\begin{array}{r}1.552 \\
{[1.606}\end{array}$ \\
\hline$\# \mathrm{~b} 2$ & SiO-Palik & $\begin{array}{c}2.470 \\
{[2.584]}\end{array}$ & $\begin{array}{c}2.926 \\
{[2.930]}\end{array}$ & $\begin{array}{c}1.900 \\
{[2.003]}\end{array}$ & $\begin{array}{c}1.628 \\
{[1.718]}\end{array}$ & $\begin{array}{c}1.559 \\
{[1.637]}\end{array}$ & $\begin{array}{r}1.547 \\
{[1.609}\end{array}$ \\
\hline$\# \mathrm{~b} 3$ & Native-Jellison & $\begin{array}{c}2.258 \\
{[2.395]}\end{array}$ & $\begin{array}{c}2.290 \\
{[2.293]}\end{array}$ & $\begin{array}{c}1.500 \\
{[1.527]}\end{array}$ & $\begin{array}{c}1.398 \\
{[1.454]}\end{array}$ & $\begin{array}{c}1.329 \\
{[1.362]}\end{array}$ & $\begin{array}{r}1.323 \\
{[1.372}\end{array}$ \\
\hline$\# \mathrm{~b} 4$ & $\begin{array}{c}\text { Sellmeier } \\
\text { fitting } \text { offset } \text { value only }\end{array}$ & $\begin{array}{c}2.214 \\
{[2.377]}\end{array}$ & $\begin{array}{c}2.308 \\
{[2.311]}\end{array}$ & $\begin{array}{c}1.431 \\
{[1.479]}\end{array}$ & $\begin{array}{l}1.368 \\
{[1.440]}\end{array}$ & $\begin{array}{c}1.308 \\
{[1.370]}\end{array}$ & $\begin{array}{r}1.301 \\
{[1.357}\end{array}$ \\
\hline
\end{tabular}


TABLE IV. Fit quality parameter, $\xi_{\mathrm{o}}$, for multi-sample fits in class $\mathrm{Ac}_{\mathrm{c}}$ with interface layers and using an adjustable Sellmeier model $\left(\mathrm{SiO}_{2}-\right.$ Sellmeier) to fit for the thermal $\mathrm{SiO}_{2}$ optical constants. (Bracketed values were calculated, without refitting, for a common spectral range of $1.5-5.3 \mathrm{eV}$.)

\begin{tabular}{|c|c|c|c|c|c|c|c|}
\hline \multirow[b]{2}{*}{$\begin{array}{l}\text { Fit } \\
\text { group }\end{array}$} & \multirow[b]{2}{*}{ Interface model } & \multicolumn{3}{|c|}{ Tabulated Si Opt Cons } & \multicolumn{3}{|c|}{ Fitted Si Opt Cons } \\
\hline & & $\begin{array}{c}\text { (i) } \\
\text { Aspnes }\end{array}$ & $\begin{array}{c}\text { (ii) } \\
\text { Jellison }\end{array}$ & $\begin{array}{c}\text { (iii) } \\
\text { Final, fit } \\
\text { \#c4(iv) }\end{array}$ & $\begin{array}{c}\text { (iv) } \\
\text { Parametric } \\
\text { Si model }\end{array}$ & $\begin{array}{c}(\mathrm{v}) \\
\lambda \text {-by- } \lambda \\
\text { Si only }\end{array}$ & $\begin{array}{c}\text { (vi) } \\
\lambda \text {-by- } \lambda \\
\text { fit all }\end{array}$ \\
\hline$\# \mathrm{c} 1$ & EMA & $\begin{array}{c}2.008 \\
{[2.112]}\end{array}$ & $\begin{array}{c}2.423 \\
{[2.426]}\end{array}$ & $\begin{array}{c}1.176 \\
{[1.269]}\end{array}$ & $\begin{array}{l}1.140 \\
{[1.167]}\end{array}$ & $\begin{array}{c}1.080 \\
{[1.086]}\end{array}$ & $\begin{array}{c}0.981 \\
{[0.979]}\end{array}$ \\
\hline$\# \mathrm{c} 2$ & SiO-Palik & $\begin{array}{c}2.024 \\
{[2.138]}\end{array}$ & $\begin{array}{c}2.464 \\
{[2.467]}\end{array}$ & $\begin{array}{c}1.193 \\
{[1.303]}\end{array}$ & $\begin{array}{c}1.142 \\
{[1.181]}\end{array}$ & $\begin{array}{c}1.080 \\
{[1.099]}\end{array}$ & $\begin{array}{c}0.977 \\
{[0.986]}\end{array}$ \\
\hline$\# \mathrm{c} 3$ & Native-Jellison & $\begin{array}{c}1.939 \\
{[2.064]}\end{array}$ & $\begin{array}{c}2.017 \\
{[2.020]}\end{array}$ & $\begin{array}{c}0.792 \\
{[0.836]}\end{array}$ & $\begin{array}{c}0.794 \\
{[0.824]}\end{array}$ & $\begin{array}{c}0.712 \\
{[0.717]}\end{array}$ & $\begin{array}{c}0.690 \\
{[0.707]}\end{array}$ \\
\hline$\# \mathrm{c} 4$ & $\begin{array}{c}\text { Sellmeier } \\
\text { fitting } \text { offset } \text { value only }\end{array}$ & $\begin{array}{c}1.922 \\
{[2.058]}\end{array}$ & $\begin{array}{c}2.033 \\
{[2.035]}\end{array}$ & $\begin{array}{c}0.774 \\
{[0.827]}\end{array}$ & $\begin{array}{c}0.774 \\
{[0.827]}\end{array}$ & $\begin{array}{c}0.691 \\
{[0.718]}\end{array}$ & $\begin{array}{c}0.678 \\
{[0.704]}\end{array}$ \\
\hline
\end{tabular}

here are at least not seriously inconsistent with such an assumption. During all fits, the silicon substrate optical constants were forced to be the same (coupled together) for each of the seven sample models regardless of whether a wavelength tabulated set was used or a parametric functional model was being fitted. With a few noted exceptions in class \#a, the bulk oxide optical constants for samples \#1-6 were forced to be the same tabulated values or to use the same Sellmeier form. When included, interface optical constants were forced to be the same for each sample model. For the native oxide sample (\#7), the overlayer was modeled using a Sellmeier functional form with an adjustable offset parameter and thickness. Because overlayer optical constants for sample \#7 were not coupled to the other samples, this sample provides detailed shape information about the silicon dielectric function but does not uniquely define amplitudes.

(2) For a particular description of the thermal oxide and interface within any of the three model classes, six different optical constant models [(i)-(vi)] for the silicon substrate were examined: (i) Aspnes' values for silicon between 1.5 and $6.0 \mathrm{eV}$, and (ii) Jellison's values between 1.48 and 5.3 $\mathrm{eV}$ were used in interpolated, tabular form. (iii) The final silicon substrate optical constants from this work $(\mathrm{Si}-$ final) over the full experimental range from 0.75 to $6.5 \mathrm{eV}$ were also examined. As a procedural matter, fits using this substrate model (iii) were performed after the final silicon optical constants for this work were determined. However, these results are presented as part of the natural progression as if they had been available beforehand. This allows a direct comparison of results using $\mathrm{Si}-\mathrm{Aspnes}, \mathrm{Si}-\mathrm{Jellison}$, and $\mathrm{Si}-$ final for the full set of oxide and interface configurations considered. (iv) A parametric functional model with 58 adjustable parameters was used that enforces KK consistency. Therefore, any fit improvements over models (i)-(iii) indicated that for the particular oxide/interface configuration being investigated there is an alternate, physically reasonable, set of silicon optical constants to consider. (v) Using the fit results from silicon substrate model (iv), the parametric silicon layer was replaced with a tabulated dielectric set which was then varied at all wavelengths (except that $\epsilon_{2}$ was fixed at zero for $E_{\mathrm{ph}}<1.0 \mathrm{eV}$ ) with all other model parameters (e.g., thicknesses, Sellmeier values) held fixed. This pro- vided a check on the quality of model (iv). If model (v) produced a significantly better fit (noticeably lower $\xi_{\mathrm{o}}$ ) that would imply that the previous parametric silicon model was too inflexible. Of course $\xi_{\mathrm{o}}$ will always be lower for model (v) as compared to (iv) over the same spectral range, because some experimental noise can be absorbed into the silicon optical constants when fitting on a wavelength-bywavelength basis. (vi) Next, using the results from model (v), the fit parameters from (iv) not related to the substrate optical constants were re-included in the fit along with the wavelength-by-wavelength silicon dielectric values. As in (v) the $\epsilon_{2}$ values for $E_{\mathrm{ph}}<1.0 \mathrm{eV}$ were fixed at zero, and this provided the only external constraint on the physicality of the resulting silicon optical constants. When fitting both tabulated silicon optical constants and thickness, the enforced KK relationship of the parametric model used in (iv) is lost. The sole reason for examining model (vi) is that it establishes a lower limit on the achievable $\xi_{\text {o }}$ value for a given oxide-interface configuration being tested. This lowest $\xi_{\text {o }}$ value does not necessarily imply a "best" fit, because the resulting optical constants are not necessarily physical.

(3) The results summarized in Tables II-IV are each the end point of a full multi-sample fit with a particular oxide, interface, and silicon description. Each multi-sample fit is reduced to two quality of fit values as follows. (It is space prohibitive to tabulate all the fit parameter values and confidence limits for each of the 54 fits examined.) Two values are presented to allow more direct comparison between this work, which covers a wider spectral range, and previously published results of Aspnes and Jellison. One $\xi_{0}$ value is for the respective fit ranges associated with silicon optical constant range: (i) ( $\mathrm{Si}-\mathrm{Aspnes}, 1.5-6.0 \mathrm{eV}$ ), (ii) ( $\mathrm{Si}-\mathrm{Jellison}$, $1.48-5.3 \mathrm{eV}$ ), (iii-vi) $(0.75-6.5 \mathrm{eV}$ ). The second (square brackets) value was calculated, without refitting, for just the data in a common optical constant range of $1.5-5.3 \mathrm{eV}$.

(4) Parameter correlation between fitted optical constants and thicknesses is always a potential problem, especially for very thin layers. The wide range of thermal oxide thicknesses examined in this multi-sample experiment is an effective way of reducing this correlation and obtaining a unique set of oxide optical constants. ${ }^{26}$ However, for very thin layers, even a multi-sample analysis may not be totally 
(a) Thermal oxide model for fit \#al(i)

\begin{tabular}{|c|c|}
\hline Glass-Palik & Fit thickness \\
\hline Si-Aspnes & \\
\hline
\end{tabular}

(b) Thermal oxide model for fit \#al(ii)

\begin{tabular}{|ll|}
\hline Glass-Palik & Fit thickness \\
\hline Si-Jellison &
\end{tabular}

(c) Thermal oxide model for fit \#al(iii)

\begin{tabular}{|ll|}
\hline Glass-Palik & Fit thickness \\
\hline Si-final &
\end{tabular}

(d) Thermal oxide model for fit \#al(iv)

\begin{tabular}{|lr|}
\hline Glass-Palik & Fit thickness \\
\hline Si-Parametric & Fit internal parameters
\end{tabular}

(e) Thermal oxide model for fit \#al(v)

\begin{tabular}{|lr|}
\hline Glass-Palik & Thickness taken from fit \#al(iv) \\
\hline Si-Tabulated & Fit at each wavelength
\end{tabular}

(f) Thermal oxide model for fit \#al(vi)

\begin{tabular}{|lr|}
\hline Glass-Palik & Fit thickness \\
\hline Si-Tabulated & Fit at each wavelength \\
\hline
\end{tabular}

(g) Thermal oxide model for fit \#a3(iii)

\begin{tabular}{|ll|}
\hline $\mathrm{SiO}_{2}$-Sellmeier & Fit thickness, offset, $\mathrm{a}, \mathrm{b}, \mathrm{c}$ \\
\hline Si-final &
\end{tabular}

(h) Native oxide model for all fits

\begin{tabular}{|l|}
\hline Native-Sellmeier \\
\hline Silicon, same as for the thermal oxide models
\end{tabular}

FIG. 5. Illustrative examples of individual sample models used for some of the analyses in fit class \#a.

effective. ${ }^{27}$ Thus in determining optical constants for a proposed $\mathrm{Si}-\mathrm{SiO}_{2}$ interface layer, one cannot expect to find an unambiguous set of optical constants. However, if correlation between the index and thickness is isolated to the thin layer, optical constants for other thicker layers may still be uniquely determined. ${ }^{26}$

(5) There have been many investigations of the nature of this interface and of oxide optical constants. A major difference between this work and most other published results is that here the Si optical constants are also allowed to vary in the fit procedure. The use of nonadjustable Si optical constants imposes a constraint on the data analysis such that the "presence" of an interface might in fact only be an analysis artifact. Thus unless it is shown to be necessary to have three (or more) distinct optical layers, one may simply be fitting for interfaces which correct for an imperfect assumption about the substrate optical constants. A systematic investigation of simple models is needed to establish the baseline from which one can infer that a real improvement comes from using a more complex model.

\section{B. Models without interfaces}

The first, and simplest, fit group (\#a1) utilized values from Glass-Palik to model the thermal oxide layers, and no interface layer was included. The results for the different silicon substrate models examined are given in the first row of Table II. For each of the three fits using fixed silicon optical constants, (i)-(iii), there were eight parameters fitted for the multi-sample analysis: six thermal oxide thicknesses and two native oxide overlayer parameters (thickness and Sellmeier offset). [See Figs. 5(a)-5(c).] Over their respective fit ranges, fits using $\mathrm{Si}-\mathrm{Aspnes}, \mathrm{Si}-\mathrm{Jellison}$, and $\mathrm{Si}-$ final produced $\xi_{\mathrm{o}}$ values of $2.970,3.208$, and 2.437. However, when calculated over a common spectral range (square brackets), the corresponding $\xi_{\text {o }}$ values were $3.138,3.213$, and 2.743. Viewed in this way the fit quality using $\mathrm{Si}-$ Aspnes is essentially the same as for $\mathrm{Si}-\mathrm{Jellison}$, and using $\mathrm{Si}$-final produces only a slightly lower $\xi_{\mathrm{o}}$. However these numbers should also be compared to $\xi_{\mathrm{o}}=0.774$ [0.827], a factor of 4 better, which can be achieved with a more sophisticated model described below. This difference in $\xi_{\mathrm{o}}$ is nicely visualized in terms of $\psi$ and $\Delta$ by comparing Fig. 2(b) and Fig. 6. Figure 6 shows the experimental and modeled data for sample \#1 (nominal $10.5 \mathrm{~nm}$ ) as part of fit \#a1(i) using $\mathrm{Si}-$ Aspnes to describe the substrate. Figure 2(b) shows data for the same sample resulting from the final fit, \#c4(iv). The fit in Fig. 6, while good, is visibly less perfect than that seen in Fig 2(b).

For fit \#a1(iv), there were 66 adjustable parameters including the eight used for fits (i)-(iii), and 58 internal to the silicon parametric model. [See Fig. 5(d).] Fit \#a1(iv) produced $\xi_{0}=1.784[1.902]$ which is notably lower than the previous fits, (i)-(iii), and indicates that the simplest model us-

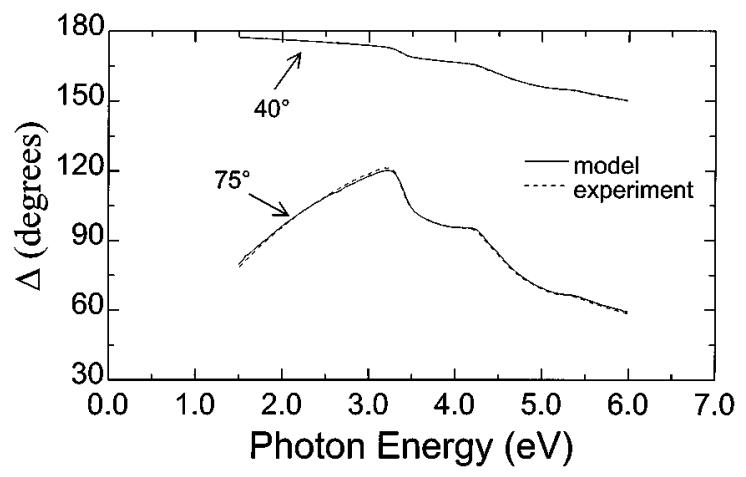

FIG. 6. Measured $\Delta$ data compared with generated data from fit \#a1(i) for sample \#1 with a nominal oxide thickness of $10.5 \mathrm{~nm}$. The optical model used $\mathrm{Si}-\mathrm{Aspnes}$ for the silicon substrate and Glass-Palik for the thermal oxide. 
ing existing silicon and oxide optical constants is not the best. When the silicon optical constants were fitted on a wavelength-by-wavelength basis in fit \#a1(v), the resulting $\xi_{\text {o }}$ was $1.674[1.690]$ and the total number of fit parameters was $600\left(290 \epsilon_{2}\right.$ values and $310 \epsilon_{1}$ values, $\epsilon_{2}=0$ for $E_{\mathrm{ph}}<1.0 \mathrm{eV}$ ). [See Fig. 5(e).] For fit \#a1(vi), 608 parameters were fitted [the 600 from \#a1(v) and the 8 from \#a1(i)]. [See Fig. 5(f).] The resulting $\xi_{\mathrm{o}}$ values of 1.653[1.780] effectively serve as a theoretical lower limit for this group of fits using Glass-Palik and no interface. The improved fit qualities of \#a1(v) and \#a1(vi) depend somewhat on the spectral region and might indicate some inflexibility of the parametric model. However because KK consistency is not enforced, the slightly better fit may have been achieved by creating a silicon optical constant set which is not physical. Furthermore, noticeably better fits were achieved using more complex models.

Fit group \#a2 is included only to establish that a Sellmeier model for the oxide can be a reasonable approximation. The fits in this group proceeded exactly as for group \#a1 except that the Glass-Sellmeier was used to model the thermal oxides instead of Glass-Palik. The similarity of $\xi_{\text {o }}$ values for all silicon models with those of fit group \#a1 indicates that the four parameter Sellmeier model used is sufficiently flexible.

Fit group \#a3 extended the previous group by allowing the four Sellmeier parameters describing the oxide to be fitted. [See Fig. 5(g).] The lower $\xi_{\text {o }}$ values for these fits, as compared to group \#a2, indicate that the Glass-Palik values may not be the optimal description for thermally grown oxide. However, even as in fit \#a3(iv) where both silicon and oxide optical constants were fitted, the resulting $\xi_{\text {o }}$ value is approximately two times larger than can be achieved when an interface layer is included.

Fit group \#a4 is a derivative of group \#a2, except that the coupling of oxide optical constants among the six thermal oxide samples was removed. Furthermore, the Sellmeier offset parameter for each of the thermal oxide samples was fit. The other three Sellmeier parameters (a, b, and c) were held fixed at the values used for Glass-Sellmeier. There are 14 fit parameters common to this group: seven oxide thicknesses and seven offset parameters. These fits produced generally higher $\xi_{\text {o }}$ values than group \#a3, which indicates that the ability to change the shape of the oxide optical constant dispersion, even when coupled across samples, is more useful than decoupling the oxide optical constants and fitting just the offset. However, the general trend is that the thinner oxide samples fit to higher offset, and thus higher index, values.

Fit group \#a5, derived from \#a4, reduced the constraints on the separate Oxide-Sellmeier models even further by allowing all four parameters to be fitted for each of the six thermal oxide samples. For this group, the only aspect tying the multi-sample fit together is that the silicon optical constants are coupled between the samples. The resulting oxide optical constants for four of the thermal oxide samples of fit \#a5(iii) shown in Fig. 7 demonstrate a monotonic decrease in index with thickness. This effect has been observed previously when using this type of model. ${ }^{6,7}$ Group \#a5 produced

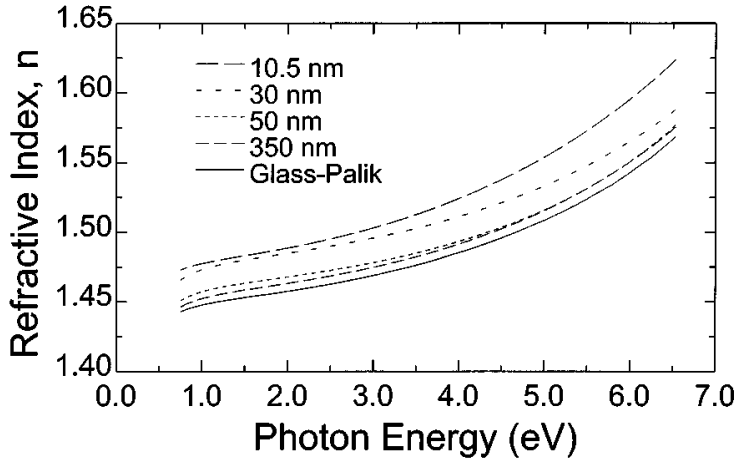

FIG. 7. Refractive index functions derived from fit \#a4(iii) for four of the thermal oxide samples compared with published values from Palik. For each of the thermal oxide samples the four Sellmeier parameters were fitted separately from the other samples.

somewhat lower $\xi_{\mathrm{o}}$ values as compared to group \#a3, but fit $\# \mathrm{a} 5$ is much more complex than \#a3 because it permits the oxide optical "constants" to be a function of thickness. Therefore, by just examining the fit results, it is not immediately obvious one should prefer the complicated oxide model procedure for group \#a5 over the procedure for group \#a3 which employed only a single, coupled set of oxide optical constants. From a physical standpoint, it is difficult to explain how an amorphous material growing away from the $\mathrm{Si}-\mathrm{SiO}_{2}$ interface could have noticeably different optical constants for different thickness. Potentially near the growing interface there may be a region with a lower oxygen to silicon ratio. However, because all the oxygen consumed at the interface to produce new oxide must first pass through the already grown oxide, it seems that the upper part of the oxide must reach a fairly stable atomic ratio and any region of partial oxidation must be atomically close to the interface.

One possible interpretation of this apparent dependence of index on thicknesses is to assume the existence of thin interfacial layer with approximately the same thickness on all samples, but with an index higher than the bulk of the oxide. $^{6}$ A higher index would be representative of incomplete oxidation (the index of $\mathrm{SiO}$ is higher than that of $\mathrm{SiO}_{2}$ ) or of roughening (the index of silicon is higher than that of $\mathrm{SiO}_{2}$ ). Furthermore, the physical process which created the interfacial layer should not depend strongly on the overall oxide thickness. Therefore, working with a simple interfacebulk description, the influence of a high index interface layer will be diluted as the overall oxide thickness increases, and the average index (apparent index if a single layer is used in the model) will approach the index of the bulk. Thus, it may be possible to explain the apparent index change in fit group \#a5 while still having optical constant sets (bulk and interface) which are the same for all thermal oxide samples. This explanation is investigated in the two remaining fit classes.

\section{Models with interfaces and fixed oxide optical constants}

Fit class \#b examines different possible descriptions for the interface while assuming that the bulk of the oxide can be modeled using existing optical constants (Glass-Palik). Re- 
(a) Thermal oxide model for fit \#bl(iii)

\begin{tabular}{|ll|}
\hline Glass-Palik & Fit thickness \\
\hline EMA & Fit thickness \\
\hline Si-final & \\
\hline
\end{tabular}

(b) Thermal oxide model for fit \#b2(iii)

\begin{tabular}{|ll|}
\hline Glass-Palik & Fit thickness \\
\hline SiO-Palik & Fit thickness \\
\hline Si-final &
\end{tabular}

(c) Thermal oxide model for fit \#b3(iii)

\begin{tabular}{|ll|}
\hline Glass-Palik & Fit thickness \\
\hline Native-Jellison & Fit thickness \\
\hline Si-final &
\end{tabular}

(d) Thermal oxide model for fit \#b4(iii)

\begin{tabular}{|lr|}
\hline Glass-Palik & Fit thickness \\
\hline Interface-Sellmeier & Fit thickness, offset \\
\hline Si-final &
\end{tabular}

(e) Thermal oxide model for fit \#c4(iv)

\begin{tabular}{|lr|}
\hline $\mathrm{SiO}_{2}$-final & \multicolumn{1}{c|}{ Fit thickness, offset, $, \mathrm{a}, \mathrm{b}, \mathrm{c}$} \\
\hline Interface-final $($ offset $=3.5)$ & Fit thickness \\
\hline Si-final & Fit internal parameters
\end{tabular}

FIG. 8. Illustrative examples of individual sample models used for some of the analyses in fit classes \#b and \#c.

sults are given in Table III. Fit class \#c will examine the need for also fitting the bulk oxide optical constants, but first baselines must be established in order to demonstrate that such a complication is required. All interface layers are optically modeled as homogenous, isotropic layers with well defined boundaries. Physically any interface would really be better represented by the grading of the effect in question, but in practice fitting ellipsometric data provides sensitivity only to the existence of a thin interface, not the exact shape of the index grade.

Fit group \#b1 employed an EMA layer to describe a roughened interface layer. [See Fig. 8(a).] The EMA assumed an equal mixture of silicon substrate and thermal oxide optical constants. (Additional work fitting the EMA fraction and depolarization value did not noticeably improve upon these results.) These fits proceeded much like those of group \#a1 except that six additional interface thickness terms were fitted. Some improvement over the group \#a1 results in Table II were noted, but they were not substantial. In group $\# \mathrm{~b} 2$, an $\mathrm{SiO}$ layer (SiO-Palik) was used to simulate an incomplete oxidation layer. [See Fig. 8(b).] These fits proceeded exactly like \#b1 with the SiO replacing the EMA optical constants, and the fit results were similar. Both the EMA and $\mathrm{SiO}$ descriptions include spectral regions where the interface is modeled as slightly absorbing.

The apparent index increase for thinner samples (fit \#a5) suggests that a transparent interface might be sufficient to produce the effect. The Native-Jellison optical constants are transparent and have an index higher than Glass-Palik. Of course using Native-Jellison to model the interface does not imply a residual native oxide at the interface. Rather the higher index noted for the native oxide may be due to incomplete oxidation which may be similar to the situation near the interface even if the physical processes involved are very different. Fits of group \#b3 include Native-Jellison interface layers, and proceeded in the same way as groups \#b1 and \#b2. [See Fig. 8(c).] The fit results were slightly better than for \#b1 or \#b2 and similar to \#a3 which allowed the oxide optical constants to vary without including an interface. Based on the results from groups \#a3 and \#b3 it is not clear which model would be preferred since fit qualities are roughly equal and, including an interface layer or fitting the oxide optical constants, are of about equal complexity. Since there appeared to be a slight improvement when a fully transparent interface was used, it seemed appropriate to examine a wider range of index values. The Native-Jellison optical constants are represented by a Sellmeier model which is similar in shape to that for Glass-Palik, but has a higher offset term. Thus in fit group \#a4, the interface was modeled using Native-Sellmeier and the interface offset value was included as a fit parameter. [See Fig. 8(d).] Inclusion of this one additional fit parameter did not improve the fit quality, however.

\section{Models with interfaces and fitted oxide optical constants}

The next model development was to include an interface layer and to simultaneously fit for the bulk oxide optical constants. The oxide was modeled using $\mathrm{SiO}_{2}-$ Sellmeier and the four Sellmeier parameters were fitted as in the group \#a3 work. Fit results are summarized in Table IV. Otherwise the fits in this class proceeded the same as in class \#b. Fit group \#c1, using an EMA interface model, produced notably lower

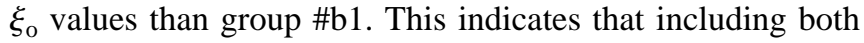
an interface and fitted oxide optical constants for the bulk is appropriate. Fit group \#c2, using an $\mathrm{SiO}$ interface, produced essentially the same fit quality as \#c1. This demonstrates that the EMA and $\mathrm{SiO}$ interface descriptions, while being quite different in nature, are not distinguishable based on the quality of the fits. Using a Native-Jellison to described the interface, \#c3, yielded even lower $\xi_{\mathrm{o}}$ values suggesting that a transparent interface is still preferable. At this point it was hoped that fit group \#c4 would reveal the proper index for 
the interface layer by fitting the offset parameter while using Native-Sellmeier optical constants model as in fit group \#b4. [See Fig. 8(e).] Just performing the fit would of course yield a result and a good fit. However, due to correlation effects, the results were somewhat ambiguous. This correlation can be easily missed, but it is essential that it be examined before claiming a unique result. In the next section, the correlation and the final results (choice of interface offset value) for fit \#c4(iv) are examined in depth.

\section{E. Correlation effects and final results}

To closely examine correlation effects one can look at the standard two parameter correlation coefficients that are calculated from the covariance matrix used in the regression fitting algorithm. ${ }^{10}$ This can provide a useful way of examining potential problems, but it can miss some correlation problems involving more than two parameters, and it does not provide much insight into the nature of the problem. More information can be derived by examining the fit quality, $\xi_{0}$, as a function of one of the fit parameters. For instance, consider a procedure which fits a number of parameters [for \#c4(iv) 77 parameters were fit] and yields a $\xi_{\text {o }}$ value and best values for the fit parameters. Next, consider holding one of the parameters fixed and fitting the other (e.g., 76) parameters around the fixed value. Then $\xi_{\mathrm{o}}$ and the other parameters can be examined as functions of the fixed parameter value. If the parameter being fixed is uncorrelated, then the $\xi_{\mathrm{o}}$ for values of the fixed parameter around its best fit value should yield a roughly parabolic minimum.

In this work, fit results were examined while fixing the Sellmeier offset value for the interface. The resulting $\xi_{\mathrm{o}}$ as a function of interface offset (not shown) did not yield a distinct minimum, and was approximately constant with values between 0.752 and 0.813 for offset values from 1.75 to 6.0. This means that the interface optical constants are correlated to some other parameters. For very thin interface layers, correlation between the interface thickness and interface index (offset) is inevitable and acceptable if the correlation is confined internally, but it is necessary to determine if correlations exist between the interface index and the silicon or bulk oxide optical constants, which are of primary interest.

First we examined the bulk oxide optical constants derived from fits with offset values of 2, 3.5, and 5. The $\mathrm{SiO}_{2}$ optical constants produced by these three fits using the Sellmeier model were virtually identical. The three sets were within $0.00035(0.025 \%)$ in refractive index of each other over the full range from 0.75 to $6.5 \mathrm{eV}$. The resulting oxide thicknesses were correlated to the interface thicknesses as expected (decreased oxide thickness for increased interface thicknesses), but the bulk $\mathrm{SiO}_{2}$ optical constants were uniquely determined. The multi-sample analysis was able to separate the bulk oxide optical constants from the interface and silicon optical constants. Having a wide range of thicknesses which had different (but dominant) interference patterns, yielded only one possible result which was shown previously as $\mathrm{SiO}_{2}$-final in Fig. 3. The correlation of interface offset with interface thickness and silicon optical constants is more complicated.

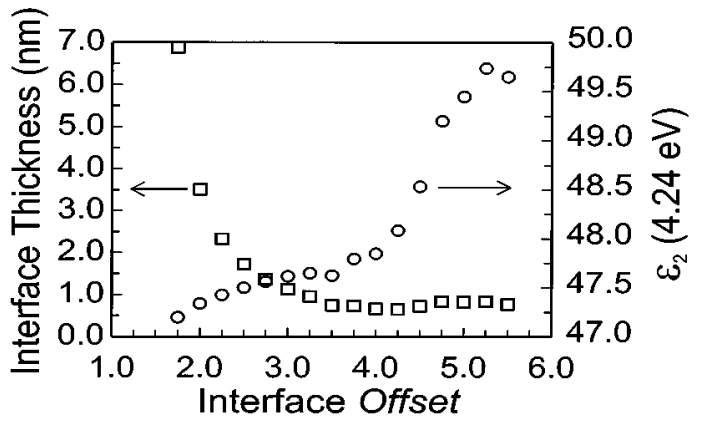

FIG. 9. Representation of correlation effects between the interface optical constants as controlled by the interface's Sellmeier offset parameter ( $x$ axis) and the resulting interface thickness for sample \#1 (left $y$ axis) and the resulting $\epsilon_{2}$ peak height in the fitted silicon optical constants (right $y$ axis). For offset values below 3.5, there is an increase in the fitted interface thickness as the interface optical constants decrease. For offset values above 3.5, correlation between the interface optical constants and silicon optical constants becomes more pronounced.

The silicon optical constants did exhibit some correlation to the interface for some interface offset values. However, based solely on the fits' $\xi_{\text {o }}$ values there is no clear method of choosing between these models. An accurate, direct measurement of a larger $\epsilon_{2}$ on a pristinely prepared sample may indicate that a proposed optical constant set has an $\epsilon_{2}$ peak that is too low, but it cannot place an absolute maximum on $\epsilon_{2}$ because some roughness or oxide might still be present. (Even optical constants from a hyper-clean $\mathrm{Si}$ surface may not be the best comparison since different physical effects may be present on such a surface which do not exist when even a small amount of oxidation is present.) Transmission measurements (which can be very accurate in describing bulk absorption properties) near the band gap have been used in other work to help constrain overlayer thickness in determining optical constants. ${ }^{2,9}$ However, the dielectric functions for different interface offset assumptions (not shown) tend to merge at lower photon energies and only a very accurate transmission measurement at around $3.0 \mathrm{eV}$ would allow a distinction to be made. Likewise, comparing extrapolated index values at long wavelengths (low $E_{\mathrm{ph}}$ ) with prism measured values will not distinguish between these possible results because the $\epsilon_{1}$ values are virtually identical in the transparent region. The consequence is that multiple sets of silicon optical constants can model the available data and do so with equal precision. Defining absolute accuracy requires an external definition (nonellipsometric), but this is the usual situation for a model dependent technique no matter how precise the measurement.

Figure 9 examines the correlation in detail revealing two primary effects. In Fig. 9, interface thickness for sample \#1 and the resulting silicon $\epsilon_{2}$ values at $4.24 \mathrm{eV}$ are plotted for the different offset values considered. The interface thicknesses for the other thermal oxide samples exhibit similar trends. For offset values below 3.5, the $\epsilon_{2}$ peak height resulting from the fit is almost constant and therefore uncorrelated to the interface offset. In this regime, the correlation is primarily between the interface thickness and offset. This exhibits a typical conservation of index-thickness product with 
increasing interface thickness with decreasing offset values for offset $<3.5$. For offset values larger than 3.5, the interface thickness becomes fairly constant and the silicon $\epsilon_{2}$ peak values begin to increase. In this regime, the correlation is no longer internal to the interface and begins to influence the substrate. Because there is no mathematically objective approach to selecting the proper offset, we have relied on other considerations in selecting an offset $=3.5$ for producing the final results (see also Section IV). First, we believe the correlation between offset and silicon optical constants is probably an artifact produced as the higher interface index for larger offsets more closely matches the substrate optical constants. Therefore, this first consideration suggests an offset of 3.5 or lower. Second, since with offset $<3.5$, the interface thickness and offset are correlated, one might as well choose the thinnest interface value that does not cause correlation problems with the substrate optical constants. (However, a thicker interface is not incompatible with earlier x-ray photoelectron spectroscopy (XPS) observations that $\sim 4 \mathrm{~nm}$ of $\mathrm{SiO}_{2}$ may be perturbed away from the interface. ${ }^{7}$ ) This second consideration suggests a large offset, hence the choice of offset $=3.5$. Of course if future measurements demonstrate that a higher $\epsilon_{2}$ value is required or if more data which target the transition region is included, this choice can be reexamined without the need for remeasurement.

Choosing the offset $=3.5$ produces an interface index of $n=2.04$ at a wavelength of $546.1 \mathrm{~nm}$ and layer thicknesses on the order of $1 \mathrm{~nm}$ which are comparable to other literature values from Taft $^{6}(n=2.8$, thickness $\sim 0.6 \mathrm{~nm})$, Aspnes ${ }^{7}$ $(n=3.2$, thickness $\sim 0.7 \mathrm{~nm})$, and Yakovlev $^{3}$ ( $n=1.84$ unannealed at $3.18 \mathrm{eV}$ ). Direct observation of the interfacial region by transmission electron microscopy (TEM) or other means can provide a generally allowable range on interface thicknesses, but one must remember that the Fresnel reflection model assumes abrupt interfaces and that distributed effects, like grading, must be modeled as a series of transitionary layers. The $\mathrm{Si}-\mathrm{SiO}_{2}$ interface is already extremely thin and splitting it into separate layers will not make the model significantly more physical in terms of describing how photons reflect from the interface. Ultimately, in the ultrathin regime, the Fresnel model is an approximation and does not incorporate the precise physics of how the transition region and the reflected photons are interacting.

\section{COMPARISON WITH PREVIOUSLY PUBLISHED SI VALUES}

Figure 10 shows the extrapolated refractive index from $\mathrm{Si}$-final compared with published values tabulated in Palik. The extrapolation to low photon energies is simple for the $\mathrm{KK}$ consistent parametric model describing $\mathrm{Si}-$ final. The index from $\mathrm{Si}$-final matches $\mathrm{Si}-\mathrm{Palik}$ very well below $0.5 \mathrm{eV}$ and is well within the scatter from the different sources tabulated. Note that this agreement occurs automatically from the analysis with the only constraints on $\mathrm{Si}$-final being the multisample analysis and the KK consistent parametric model being fit using data from 0.75 to $6.5 \mathrm{eV}$.

Figure 11 shows an extinction coefficient (imaginary part of the refractive index) plotted for $\mathrm{Si}-$ final and five other sources. The relative merits of the different optical con-

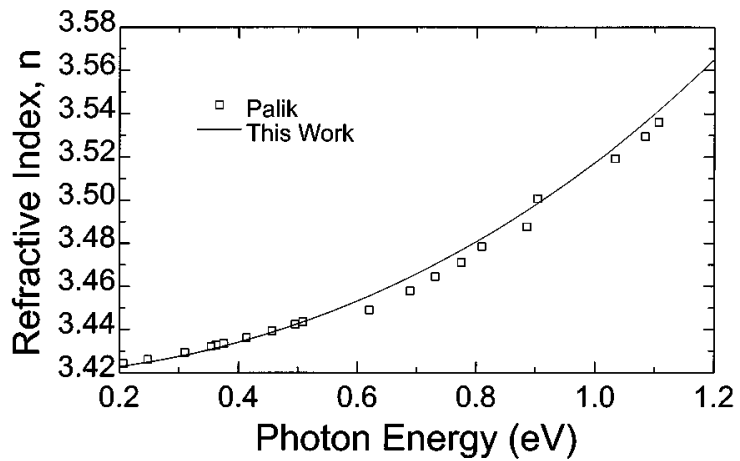

FIG. 10. Comparison of published refractive index values for silicon with extrapolated optical constants from the parametric model used to describe the final silicon optical constants from this work (Si-final). Palik's tabulated values reference four different sources.

stant sets were discussed previously in Section IV. The agreement between $\mathrm{Si}-$ final and $\mathrm{Si}-\mathrm{McFarlane}$ is intriguing, but it is probably coincidental. On a wavelength-bywavelength basis there is insufficient sensitivity in these ellipsometric measurements to determine the extinction coefficient precisely for such small values. Only the parametric model describing $\mathrm{Si}-$ final is sufficiently smooth on this scale to make a comparison. The agreement between $\mathrm{Si}-\mathrm{Jellison}$ and $\mathrm{Si}-\mathrm{Dash}$ is expected since Jellison explicitly normalized his results to match Dash. Similarly $\mathrm{Si}-$ Aspnes incorporates $\mathrm{Si}-\mathrm{Dash}$ values around $1.5 \mathrm{eV} .^{1}$

All of the proceeding results have come as the end point of a multi-sample analysis. In practice one most often wishes to determine only a layer's thickness using existing optical constants. Therefore, the impact of using the different optical models on a sample-by-sample basis has also been exam-

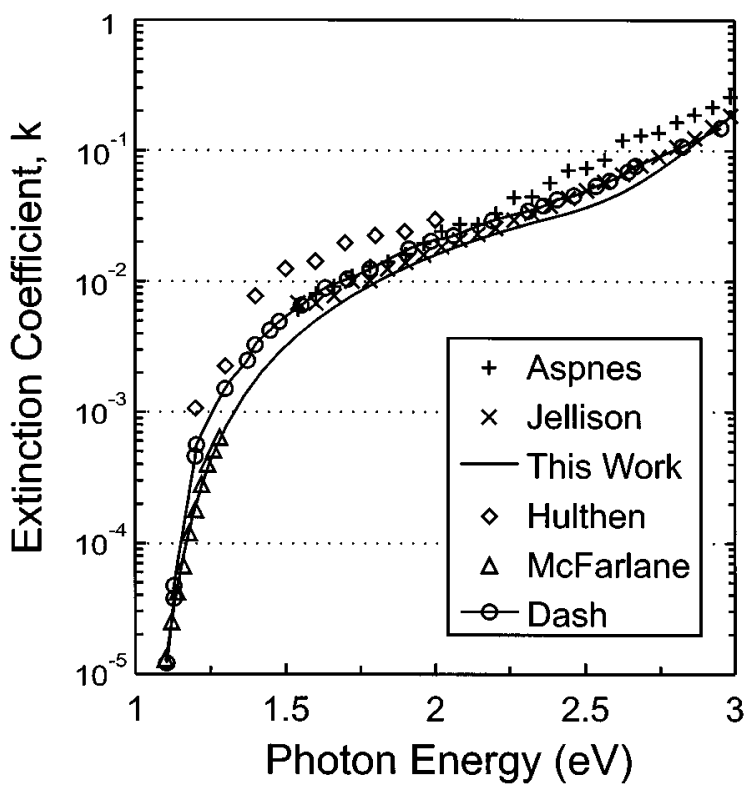

FIG. 11. Near band gap extinction coefficient from this work compared with other published values. The results of Aspnes and Jellison are from ellipsometric measurements. The work of Hulthèn, McFarlane, and Dash are from intensity transmission measurements. 
TABLE V. Sample-by-sample fit results using models without interfaces. Thicknesses in nm, FOM [Eq. (3)] in $\mathrm{nm}$ in parentheses.

\begin{tabular}{|c|c|c|c|c|c|c|}
\hline \multirow[b]{2}{*}{$\begin{array}{l}\text { Sample } \\
\text { No. }\end{array}$} & \multirow[b]{2}{*}{$\begin{array}{l}\text { Nominal } \\
t \text {-oxide }(\mathrm{nm})\end{array}$} & \multirow[b]{2}{*}{ Fit results } & \multicolumn{4}{|c|}{ Sample Models } \\
\hline & & & $\begin{array}{l}\mathrm{SiO}_{2}-\text { final } \\
\mathrm{Si}-\text { Aspnes }\end{array}$ & $\begin{array}{l}\mathrm{SiO}_{2} \text {-final } \\
\mathrm{Si} \text {-Jellison }\end{array}$ & $\begin{array}{c}\mathrm{SiO}_{2}-\text { final } \\
\mathrm{Si}-\text { final }\end{array}$ & $\begin{array}{l}\text { Glass-Palik } \\
\text { Si-final }\end{array}$ \\
\hline 1 & 10.5 & $\underset{t \text {-oxide }}{\xi_{\mathrm{o}}}$ & $\begin{array}{c}2.610 \\
11.14(0.014)\end{array}$ & $\begin{array}{c}2.110 \\
11.31(0.011)\end{array}$ & $\begin{array}{c}1.232 \\
11.33(0.006)\end{array}$ & $\begin{array}{c}1.329 \\
11.39(0.007)\end{array}$ \\
\hline 2 & 14.5 & $\underset{t \text {-oxide }}{\xi_{\mathrm{o}}}$ & $\begin{array}{c}2.119 \\
14.68(0.014)\end{array}$ & $\begin{array}{c}1.694 \\
14.87(0.011)\end{array}$ & $\begin{array}{c}1.100 \\
14.89(0.007)\end{array}$ & $\begin{array}{c}1.224 \\
14.97(0.008)\end{array}$ \\
\hline 3 & 35 & $\underset{t \text {-oxide }}{\xi_{\mathrm{o}}}$ & $\begin{array}{c}1.827 \\
34.41(0.015)\end{array}$ & $\begin{array}{c}1.616 \\
34.60(0.013)\end{array}$ & $\begin{array}{c}1.870 \\
34.61(0.016)\end{array}$ & $\begin{array}{c}2.334 \\
34.82(0.012)\end{array}$ \\
\hline 4 & 50 & $\begin{array}{c}\xi_{\mathrm{o}} \\
t \text {-oxide }\end{array}$ & $\begin{array}{c}1.518 \\
49.60(0.009)\end{array}$ & $\begin{array}{c}1.054 \\
49.74(0.006)\end{array}$ & $\begin{array}{c}1.226 \\
49.719(0.007)\end{array}$ & $\begin{array}{c}1.907 \\
50.06(0.011)\end{array}$ \\
\hline 5 & 100 & $\begin{array}{c}\xi_{\mathrm{o}} \\
t \text {-oxide }\end{array}$ & $\begin{array}{c}3.870 \\
100.27(0.021)\end{array}$ & $\begin{array}{c}4.159 \\
100.47(0.023)\end{array}$ & $\begin{array}{c}3.537 \\
100.48(0.020)\end{array}$ & $\begin{array}{c}4.84 \\
101.12(0.027)\end{array}$ \\
\hline 6 & 350 & $\begin{array}{c}\xi_{\mathrm{o}} \\
t \text {-oxide }\end{array}$ & $\begin{array}{c}3.372 \\
350.88(0.024)\end{array}$ & $\begin{array}{c}3.572 \\
351.02(0.026)\end{array}$ & $\begin{array}{c}3.084 \\
351.03(0.022)\end{array}$ & $\begin{array}{c}3.983 \\
353.28(0.029)\end{array}$ \\
\hline
\end{tabular}

ined. The data for each of the thermal oxide samples were analyzed to obtain a single oxide thickness using four models with the results summarized in Table V. For each sample, the data from 1.5 to $5.3 \mathrm{eV}$ was fitted for the oxide thickness alone. Models using $\mathrm{Si}-$ Jellison and $\mathrm{Si}-$ final for the substrate optical constants produced virtually identical (within $0.03 \mathrm{~nm}$ ) thickness results. The results using $\mathrm{Si}-$ Aspnes produce systematically lower oxide thicknesses with an average difference of $0.18 \mathrm{~nm}$. This result would be fully expected if the $\mathrm{Si}-\mathrm{Aspnes}$ optical constants internally retained the effect of $0.18 \mathrm{~nm}$ of oxide. If Aspnes' original data were reanalyzed assuming the presence of this small amount of oxide the results for all three models without interfaces (first three result columns of Table V) would be extremely consistent.
The effect of using $\mathrm{SiO}_{2}$-final instead of Glass-Palik for the oxide optical constants is presented in the last column of Table V. The best fit oxide thicknesses were obtained using a Glass-Palik average $0.6 \%$ higher than the corresponding values when using $\mathrm{SiO}_{2}$-final. This is not unexpected because the Glass-Palik refractive index is about $0.4 \%$ lower than for $\mathrm{SiO}_{2}$-final. The data for each of the eight samples were also analyzed using models with an interface (Interface-final) and a bulk oxide $\left(\mathrm{SiO}_{2}\right.$-final). Results are summarized in Table VI. Comparing Tables V and VI, for all samples and substrate optical constant sets, the fit quality is better ( $\xi_{o}$ lower) when an interface is included. This is expected because there is an extra adjustable parameter when fitting the interface thickness. That the fit quality

TABLE VI. Sample-by-sample fit results using models with interfaces. The bulk oxide is modeled using $\mathrm{SiO}_{2}$-final and the interface is modeled with Interface-final. Thicknesses in $\mathrm{nm}$, FOM [Eq. (3)] in $\mathrm{nm}$ in parentheses.

\begin{tabular}{|c|c|c|c|c|c|}
\hline \multirow[b]{2}{*}{$\begin{array}{c}\text { Sample } \\
\text { No. }\end{array}$} & \multirow[b]{2}{*}{$\begin{array}{l}\text { Nominal } \\
t \text {-oxide } \\
(\mathrm{nm})\end{array}$} & \multirow[b]{2}{*}{ Fit results } & \multicolumn{3}{|c|}{ Substrate Optical Constants } \\
\hline & & & $\begin{array}{c}\mathrm{SiO}_{2}-\mathrm{final} \\
\text { Interface-final } \\
\mathrm{Si}-\text { Aspnes }\end{array}$ & $\begin{array}{c}\mathrm{SiO}_{2}-\text { final } \\
\text { Interface-final } \\
\mathrm{Si} \text {-Jellison }\end{array}$ & $\begin{array}{c}\mathrm{SiO}_{2}-\text { final } \\
\text { Interface-final } \\
\quad \mathrm{Si} \text {-final }\end{array}$ \\
\hline \multirow{3}{*}{1} & \multirow{3}{*}{10.5} & $\xi_{\mathrm{o}}$ & 2.595 & 2.048 & 0.685 \\
\hline & & $t$-oxide & $10.84(0.159)$ & $10.80(0.125)$ & $10.29(0.041)$ \\
\hline & & $t$-interface & $0.24(0.124)$ & $0.40(0.097)$ & $0.81(0.032)$ \\
\hline \multirow{3}{*}{2} & \multirow{3}{*}{14.5} & $\xi_{\mathrm{o}}$ & 2.089 & 1.623 & 0.576 \\
\hline & & $t$-oxide & $14.26(0.147)$ & $14.31(0.114)$ & $13.79(0.040)$ \\
\hline & & $t$-interface & $0.33(0.114)$ & $0.44(0.088)$ & $0.85(0.031)$ \\
\hline \multirow{3}{*}{3} & \multirow{3}{*}{35} & $\xi_{\mathrm{o}}$ & 1.463 & 1.034 & 0.584 \\
\hline & & $t$-oxide & $33.68(0.060)$ & $33.78(0.042)$ & $33.41(0.024)$ \\
\hline & & $t$-interface & $0.63(0.0500)$ & $0.70(0.035)$ & $1.01(0.020)$ \\
\hline \multirow{3}{*}{4} & \multirow{3}{*}{50} & $\xi_{\mathrm{o}}$ & 1.442 & 0.988 & 0.643 \\
\hline & & $t$-oxide & $49.33(0.049)$ & $49.54(0.034)$ & $49.13(0.022)$ \\
\hline & & $t$-interface & $0.27(0.047)$ & $0.20(0.032)$ & $0.57(0.021)$ \\
\hline \multirow{3}{*}{5} & \multirow{3}{*}{100} & $\xi_{\mathrm{o}}$ & 1.763 & 1.742 & 1.049 \\
\hline & & $t$-oxide & $99.05(0.038)$ & $99.14(0.038)$ & $99.28(0.023)$ \\
\hline & & $t$-interface & $1.14(0.035)$ & $1.24(0.034)$ & $1.12(0.021)$ \\
\hline \multirow{3}{*}{6} & \multirow{3}{*}{350} & $\xi_{\mathrm{o}}$ & 2.132 & 2.060 & 1.083 \\
\hline & & $t$-oxide & $349.58(0.066)$ & $349.58(0.064)$ & $349.58(0.034)$ \\
\hline & & $t$-interface & $1.18(0.058)$ & $1.32(0.056)$ & $1.32(0.030)$ \\
\hline
\end{tabular}


would improve the most when $\mathrm{Si}$-final was used for the substrate was also expected because $\mathrm{Si}$-final was derived from a multi-sample analysis which included an interface layer. In fact, if $\xi_{\text {o }}$ was not noticeably lower when using $\mathrm{Si}$-final, there would be no justification for using that set of optical constants over $\mathrm{Si}-\mathrm{Aspnes}$ or $\mathrm{Si}-$ Jellison.

In practice, using the simpler no-interface model as in Table $\mathrm{V}$ will probably be the most convenient, and in that case the choice of substrate optical constants will not be a dominant factor in achieving high precision. Using $\mathrm{Si}-$ Aspnes will result in oxide thicknesses about $0.18 \mathrm{~nm}$ lower than would be obtained using $\mathrm{Si}-$ Jellison or $\mathrm{Si}-$ final. (This $0.18 \mathrm{~nm}$ difference is consistent with Aspnes' more recent $\mathrm{NH}_{4} \mathrm{~F}$ surface preparation which indicated that the earlier $\mathrm{Si}$ samples retained a residual overlayer or roughness that optically could be represented by $0.2 \mathrm{~nm}$ of $\mathrm{SiO}_{2} \cdot{ }^{24}$ ) Using $\mathrm{SiO}_{2}$-final to model the oxide will yield oxide thicknesses about $0.6 \%$ lower than Glass-Palik would. With an interface included, the agreement between models using $\mathrm{Si}-\mathrm{Jellison}$ and $\mathrm{Si}$-final is still reasonable. For the different substrate models, the fitted interface thicknesses exhibit similar trends for the different samples, but only for fits using $\mathrm{Si}$-final does $\xi_{\text {o }}$ drop significantly below the value obtained when the interface is fixed at zero thickness (compare Tables V and VI). As a practical matter, using a single layer oxide model with any of the three silicon optical constant sets is a reasonable way to maintain quality control on thickness. However, using $\mathrm{Si}$-final with the interface model in conjunction with (not in place of) the single layer model might provide additional information about interface quality. However, only if inclusion of the interface layer improves the data fit can such conclusions be considered.

\section{CONCLUSIONS}

Using a self-contained multi-sample analysis, KK consistent optical constants for silicon have been determined between 0.75 and $6.5 \mathrm{eV}$, which are in agreement with other nonellipsometric measurements. These new values exhibit some discrepancies when compared with Jellison's published values. However when used to obtain an oxide thickness using a simple one layer model, the resulting oxide thickness is the same regardless of the choice of substrate optical constants. In this same way, these new optical constants are consistent with Aspnes' measurement if one accepts that $0.18 \mathrm{~nm}$ of oxide (or an optically equivalent roughness) was incorporated into Aspnes' published values. Utilizing a fully spectroscopic multi-sample approach, optical constants for thermally grown $\mathrm{SiO}_{2}$ (thicknesses from $10.5 \mathrm{~nm}$ to 3500 $\mathrm{nm}$ ) were obtained which are slightly higher in index
$(+0.4 \%)$ as compared to published values for bulk $\mathrm{SiO}_{2}$ glass. This difference is slightly higher than reported by Aspnes $(+0.2 \%){ }^{7}$ Furthermore, this difference was shown to be independent of the exact model chosen for the interfacesubstrate combination. This work also demonstrated that the best model for the thermally grown $\mathrm{Si}-\mathrm{SiO}_{2}$ material system includes an interface layer of intermediate optical constants. For the high quality samples examined, this interface could be accounted for by a layer in the sub-nanometer range. The exact interface nature was not uniquely discernible except that nonabsorbing optical constants for the interface produced slightly better fits.

${ }^{1}$ D. E. Aspnes and A. A. Studna, Phys. Rev. B 27, 7466 (1983).

${ }^{2}$ G. E. Jellison, Jr., Opt. Mater. 1, 41 (1992).

${ }^{3}$ V. A. Yakovlev and E. A. Irene, J. Electrochem. Soc. 139, 1450 (1992); V. A. Yakovlev, Q. Liu, and E. A. Irene, J. Vac. Sci. Technol. A 10, 427 (1992).

${ }^{4}$ E. A. Irene, Thin Solid Films 233, 96 (1993).

${ }^{5}$ N. V. Nguyen, D. Chandler-Horowitz, P. M. Amirtharaj, and J. G. Pellegrino, Appl. Phys. Lett. 64, 2688 (1994).

${ }^{6}$ E. A. Taft and L. Cordes, J. Electrochem. Soc. 126, 131 (1979).

${ }^{7}$ D. E. Aspnes and J. B. Theeten, Phys. Rev. Lett. 43, 1046 (1979); J. Electrochem. Soc. 127, 1359 (1980).

${ }^{8}$ R. M. A. Azzam and N. M. Bashara, in Ellipsometry and Polarized Light (North-Holland, New York, 1977), Chap. 4.

${ }^{9}$ C. M. Herzinger, P. G. Snyder, B. Johs, and J. A. Woollam, J. Appl. Phys. 77, 1715 (1995).

${ }^{10}$ W. H. Press, B. P. Flannery, S. A. Teukolsky, and W. T. Vetterling, in Numerical Recipes: The Art of Scientific Computing (Cambridge University Press, Cambridge MA, 1988), Chap. 14.

${ }^{11}$ G. E. Jellison, Jr., Appl. Opt. 30, 3354 (1991).

${ }^{12}$ P. G. Snyder, M. C. Rost, G. H. Bu-Abbud, and J. A. Woollam, J. Appl. Phys. 60, 3293 (1986).

${ }^{13}$ W. A. McGahan, B. Johs, and J. A. Woollam, Thin Solid Films 234, 443 (1993).

${ }^{14}$ H. R. Philipp, in Handbook of Optical Constants of Solids, edited by E. D. Palik (Academic, New York, 1985), p. 749.

${ }^{15}$ B. Brixner, J. Opt. Soc. Am. 57, 674 (1967); I. H. Malitson, ibid. 55, 1205 (1965).

${ }^{16}$ H. R. Philipp, Solid State Commun. 4, 73 (1966); J. Phys. Chem. Solids 32, 1935 (1971).

${ }^{17}$ D. E. Edwards, in Handbook of Optical Constants of Solids, edited by E. D. Palik (Academic, New York, 1985), p. 547.

${ }^{18}$ R. Hulthèn, Phys. Scr. 12, 342 (1975).

${ }^{19}$ G. G. McFarlane and V. Roberts, Phys. Rev. 98, 1965 (1955).

${ }^{20}$ W. C. Dash and R. Newman, Phys. Rev. 99, 1151 (1955).

${ }^{21}$ D. E. Aspnes, in Handbook of Optical Constants of Solids, edited by E. D. Palik (Academic, New York, 1985), Chap. 5, p. 104.

${ }^{22}$ H. R. Philipp, in Handbook of Optical Constants of Solids, edited by E. D. Palik (Academic, New York, 1985), p. 765.

${ }^{23}$ V. Nayar, W. Y. Leong, C. Pickering, A. J. Pidduck, R. T. Carline, and D. J. Robbins, Appl. Phys. Lett. 61, 1304 (1992).

${ }^{24}$ T. Yasuda and D. E. Aspnes, Appl. Opt. 33, 7435 (1994).

${ }^{25}$ C. M. Herzinger, B. Johs, and J. A. Woollam (unpublished).

${ }^{26}$ C. M. Herzinger, H. Yao, P. G. Snyder, F. G. Celii, Y.-C. Kao, B. Johs, and J. A. Woollam, J. Appl. Phys. 77, 4677 (1995).

${ }^{27}$ C. M. Herzinger, P. G. Snyder, F. G. Celii, Y.-C. Kao, D. Chow, B. Johs, and J. A. Woollam, J. Appl. Phys. 79, 2663 (1996). 